\section{Detection of fish allergen by droplet digital PCR}

Cinzia Daga, Simona Cau, Maria Giovanna Tilocca, Barbara Soro, Aldo Marongiu, Bruna Vodret

Food Safety Department, Institute for Experimental Veterinary Medicine of Sardinia, Sassari, Italy

\begin{abstract}
Fish is one of fourteen allergens that must be highlighted on the label within the ingredients list. The European regulation is very restrictive to allergens with zero tolerance. Therefore, it is important to establish sensitive and specific methods for detecting fish allergen. Applicability to detect and quantify fish allergen by droplet digital polymerase chain reaction (ddPCR) has been evaluated in this work. Genomic DNA of three species belonging to the most common fish families were analyzed. PCR primers were designed to amplify a $166 \mathrm{bp}$ region of the $18 \mathrm{~S}$ rRNA gene. Comparative studies were performed to establish the optimal primer and probe concentrations. Annealing temperature was determined by using thermal gradient. The results have shown good applicability of the optimized 18S rRNA gene-method to detect and quantify small amounts of the target in samples analyzed. However, validation studies are needed in order to apply ddPCR technology for routine allergens analysis.
\end{abstract}

\section{Introduction}

In human diet, fish is a valuable source of essential amino acids, polyunsaturated fatty acids, and lipid-soluble vitamins.

Although its nutritional benefit, fish is also one of the most important triggers of severe food-allergic reactions. Fish allergy is a pathophysiological, IgE-mediated immune response to specific fish proteins. The major fish allergens are the parvalbumins, that share the identity of sequences between 61$93 \%$ among the various species. There are numerous documented cases of allergy to one specific or all species of fish. The great diversity of species consumed, often regional and the great heterogeneity of the methods of diagnosis, makes difficult to understand which is the threshold limit over which to protect the consumer.

Numerous studies have estimated the prevalence of fish allergy, usually ranging from 0.3-0.5\% (Koppelman and Hefle Sue, 2006).
The symptoms of this allergy appear within 60 minutes of exposure and include acute and generalized urticaria, nausea, vomiting, abdominal cramps, diarrhea, wheezing and asthma. In the most severe cases, anaphylaxis shocks can potentially life threatening.

Small amounts such as milligrams of protein can immediately lead to allergic reactions. The only proven and effective treatment is to conduct a diet free of fish and their derivatives. To protect allergic people, European legislation demands the obligatory labelling of 14 allergenic ingredients, including fish, by Annex II of Regulation (EU) $N^{\circ} 1169 / 2011$ (Regulation (EU) $N^{\circ} 11$ 69/2011). Current European legislation does not define allergen threshold values also known as levels action. However, some products on the market could contain traces of allergens due to cross-contaminations during the food manufacturing processes. Issues related to extractability and matrix effects remain a permanent challenge. Therefore, accurate, sensitive and fast detection methods that permit the direct recognition of allergens in food samples are highly recommendable.

For detecting fish allergen, the most common techniques used are protein-based and DNA-based methods. The first as the enzyme-linked immunosorbent assay (ELISA) is a system based on the detection of the major fish allergenic protein, parvalbumin (Houhoula et al., 2015). The second such as Real-Time quantitative PCR (qPCR), is a specific, sensitive approach for detecting and for quantification of DNA. The main advantage of the PCR methods is that they are not sensitive to factors such as pressure and heat, which can produce changes in the protein conformation and can inhibit its detection.

Some of the Real-Time PCR limitation, including certified standard and inhibition factor, have been proposed to overcome using digital PCR.

An approach, named dropled digital PCR (ddPCR), combines partitioning of the PCR mix test into several thousands or millions of individual droplets, in a water-oil emulsion. After end- point PCR amplification, each partition is scrutinized and defined as positive (presence of PCR product) or negative (absence of PCR product), and it is then calculated directly from the ratio of positive to total partitions, using binomial Poisson statistics (Morrisette et al., 2013). Use of ddPCR provides higher sensitivity, more accurate data in low quantities of target DNA and more tolerance to inhibitors. ddPCR has already been applied for monitoring transgenic presence in complex food and feed matrices. The higher
Correspondence: Cinzia Daga, Food Safety Department, Institute for Experimental Veterinary Medicine of Sardinia, Via Duca degli Abruzzi, 8, 07100 Sassari SS, Italy. Tel.: +39.079.2892332 - Fax: +39.079.2892324. E-mail: cinziadaga@alice.it

Key words: Food allergy reaction, Fish allergen, Droplet digital PCR.

Contributions: the authors contributed equally. Conflict of interest: the authors declare no potential conflict of interest.

Funding: none.

Received for publication: 28 December 2017. Revision received: 21 May 2018.

Accepted for publication: 30 August 2018.

This work is licensed under a Creative Commons Attribution-NonCommercial 4.0 International License (CC BY-NC 4.0).

CCopyright C. Daga et al., 2018

Licensee PAGEPress, Italy

Italian Journal of Food Safety 2018; 7:7264

doi:10.4081/ijfs.2018.7264

sensitivity of ddPCR has been reported for examining population dynamics of bacteria in soil and waters (Kim et al., 2014; Cao et al., 2015), in medicine to quantify HIV virus (Strain et al., 2013), to detect tumor (Shoda et al., 2017), environment (Hyun-Gwan et al., 2017) and traceability of products (Scollo et al., 2016; Junan et al., 2017).

To date the absence of fish allergens certified reference materials and the presence of inhibitors in food complex matrix suggest that ddPCR could be used as suitable technologies for allergens analysis. The aim of this work was to study the applicability of ddPCR on fish samples.

\section{Materials and Methods}

DNA from species: Salmo salar, Gadus morhua, Scomber scombrus, Todarodes sagittatus and Penaeus kerathurus was extracted from $200 \mathrm{mg}$ of fresh or frozen tissue of whole-animals collected from local market. Species identification was based on labelling standards of regulation (CE) 11 december 2013, n. 1379. A modified cetyltriammonium bromide (CTAB) protocol according to the report of Tezlaff et al. (2017) was used. Quantity and quality DNA were estimated at $\lambda=260 \mathrm{~nm}$ and by the ratio DO 260/DO280 using Synergy multi-mode microplate reader (BioTeK Instrument, Inc., Vermont, USA). DNA solution was frozen at 
$-20^{\circ} \mathrm{C}$ until use it for downstream reactions.

A ddPCR protocol targeting 18S rDNA was used to develop detection of fish allergen according to the report of Herrero et al. (2014). AJ 427629.1 Salmo salar 18S rRNA gene sequence was used as target for the design of primers P forw: GTACACACG GCCGGTACAGT and P rev: CATGGGTT TTGGGTCTGGATAA 18.S rDNA sequences alignment was performed to identify highly conserved common region to the species of fish, more often used in fish food using Bioedit Software (http://www.mbio.ncsu. edu/BioEdit/BioEdit.html v7.0.5). Primer were drawn using Primer 3 plus software (http://www. bioinformatics.nl/cgi-bin/primer 3 plus/primer3plus v.0.4.0). The probe was the same used in the study of Herrero et al. (2014) with labelling the 5'-terminal nucleotides with 6- carboxy- fluoresceine (FAM) reporter dye and the 3 'terminal nucleotide with non-fluorescent quencher (Sigma-Aldrich).

Primers and probe were first tested in Real-time PCR $\left(10 \mathrm{~min}\right.$ at $95^{\circ} \mathrm{C}$, followed by 35 cycles of $15 \mathrm{~s}$ at $95^{\circ} \mathrm{C}$, and $1 \mathrm{~min}$ at $60^{\circ} \mathrm{C}$ ). The reactions were carried out in $20 \mu \mathrm{L}$ containing: $10 \mu \mathrm{L}$ of $1 \times$ TaqMan Universal PCR Master MixII (Thermo Fisher scientific), $900 \mathrm{nM}$ of each primer, $250 \mathrm{nM}$ of probe, 6'-carboxyfluorescein (6-FAM) and on 3'-end with a not fluorescent quencher; DNA and RNA free water. qPCR reactions were performed in triplicate and were carried out by using ABI PRISM 7900 HT Sequence Detection system.

The reference material SureFood $\AA$ QUANTARD 40 (R-biopharm) containing fish and all potentially allergenic food ingredients (except for mollusks, lactose and sulphur dioxide) in a concentration of 40 ppm as standard reference fish material for all qPCR runs was also used. All ddPCR experiments were carried out by using QX200 Droplet Digital PCR (ddPCR ${ }^{\mathrm{TM}}$ ) System - Bio-Rad. The method was optimized using different concentrations of primers $(900 \mathrm{nM}$ and $600 \mathrm{nM})$ and probe $(250 \mathrm{nM}$ and $160 \mathrm{nM})$.The annealing temperature for each assay was determined by using thermal gradient from $55^{\circ} \mathrm{C}$ to $65^{\circ} \mathrm{C}$ and from 58 to $60^{\circ} \mathrm{C}$. Then, $600 \mathrm{nM}$ primers, $160 \mathrm{nM}$ probe concentrations and a $58^{\circ} \mathrm{C}$ annealing temperature were used. ddPCR reaction mixtures included $10 \mu \mathrm{L}$ of $2 \mathrm{X}$ ddPCR master mix and optimized concentrations of primer and probe in a $20 \mu \mathrm{L}$ final volume. Ten-fold serial dilutions of DNA from the three fish species were tested in qPCR and ddPCR runs. For ddPCR technology, the absolute quantification of DNA per sample (copies $/ \mu \mathrm{L}$ ) was processed using QuantaSoft (v.1.7.4.091).

The linear relationship was produced by plotting respectively log DNA per reaction against the quantitation cycle $(\mathrm{Cq})$ and by plotting quantity of pg DNA against copy number concentration.

\section{Results}

DNA from three fish species was amplified in Real-Time. qPCR with strong fluorescence and only a specific $166 \mathrm{bp}$ target located in $18 \mathrm{~S}$ region was obtained. Conversely, no amplification of DNA from the mollusk Todarodes sagittatus and from the crustacean Penaeus kerathurus, was obtained in both methods as expected.

Discrimination between positive and negative droplets was increased in ddPCR by using different concentrations of probe and primers (data not shown).

The best annealing temperature for the three fish species was in the range $58^{\circ} \mathrm{C}$ to $60^{\circ} \mathrm{C}$ and the optimum annealing temperature was $58^{\circ} \mathrm{C}$ (Figure 1).

PCR additional population of droplets (green droplet) with fluorescence values between the true positive (blue droplet) and negatives (grey droplet) in 2-D fluorescence plot were highlighted (Figure 2) and it could be due to variability inside species.

Fish DNA close to 0.18 pg were clearly detected by ddPCR compared to qPCR analysis. For the same amount of DNA, a Cq value of 37.98 was obtained with the last method (data not shown). ddPCR data have shown a linear relationship $\left(\mathrm{R}^{2}=0.9998\right)$ between pg DNA against copy number concentration (Figure 3).

\section{Discussion}

EC No 1169/2011 establishes the obligation to label for 14 allergens, including fish, even if the threshold values are not defined.

Any fish ingredient of food may be called fish, provided that the name and presentation of such food does not refer to a specific species. For this reason, 18S rRNA sequences of fish species were selected and aligned to find DNA homologies and to design primers to locate a short amplicon as a target of fish presence. ddPCR was tested to detect a sensitive screening method for fish allergen in foods to prevent the allergy reaction in consumers.

Low levels of nucleic acids and PCR

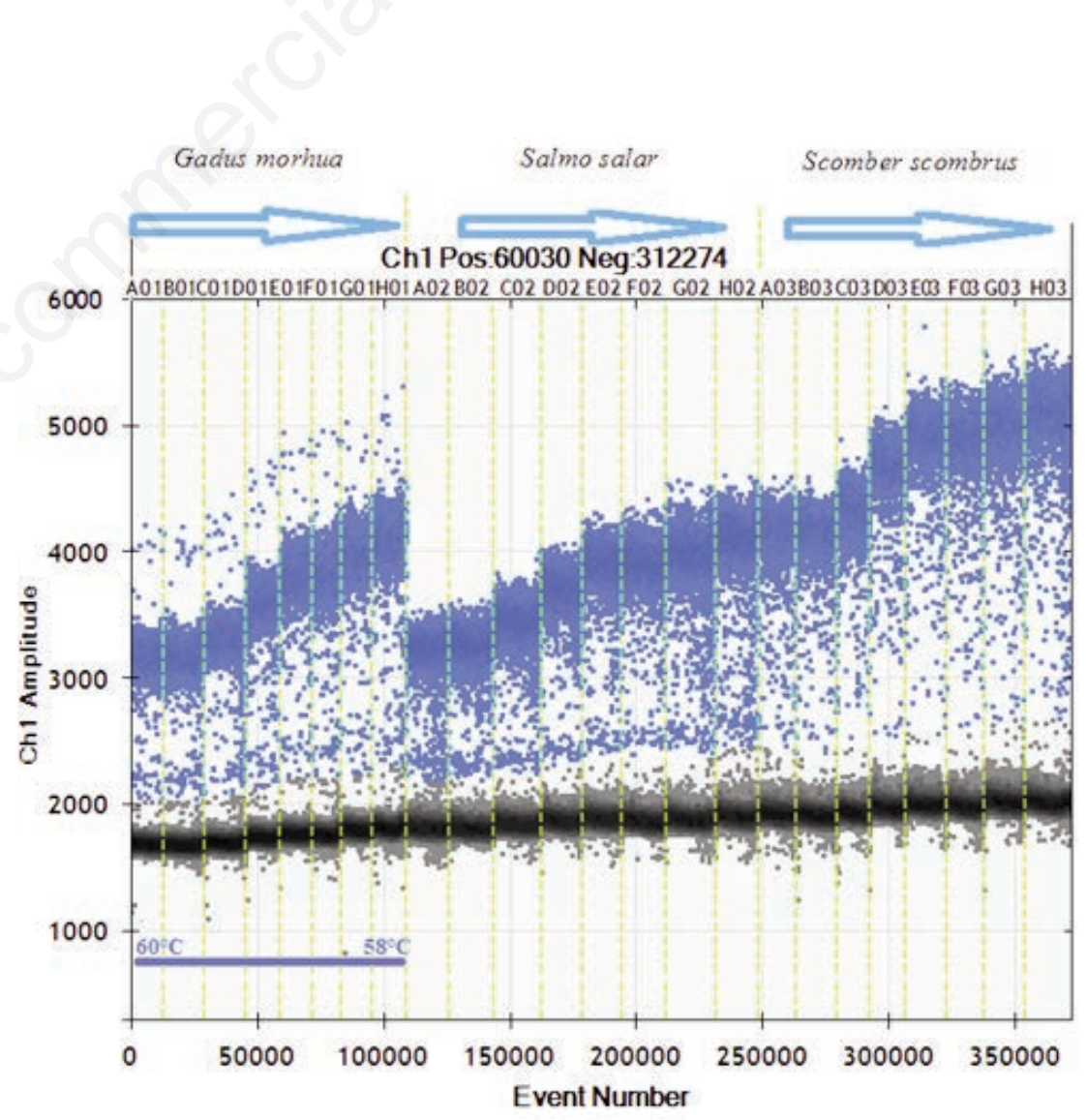

Figure 1. Three fish species Gadus morhua, Salmo salar, Scomber scombrus gradient annealing from 58 to $60^{\circ} \mathrm{C}$ in ddPCR. 
inhibitors represent a major issue affection performance in qPCR over ddPCR. Moreover, certified standards are necessary. ddPCR method overcomes these issues.

Additional population of droplets with fluorescence values between the true positive and negatives were highlighted in 2-
D fluorescence plot (Figure 2). The possible sources of such intermediate droplets including suboptimal PCR amplification are due to sequence variances, nonspecific amplification and so on (Witte et al., 2016). This additional amplification was not detected in a standard real time PCR reaction

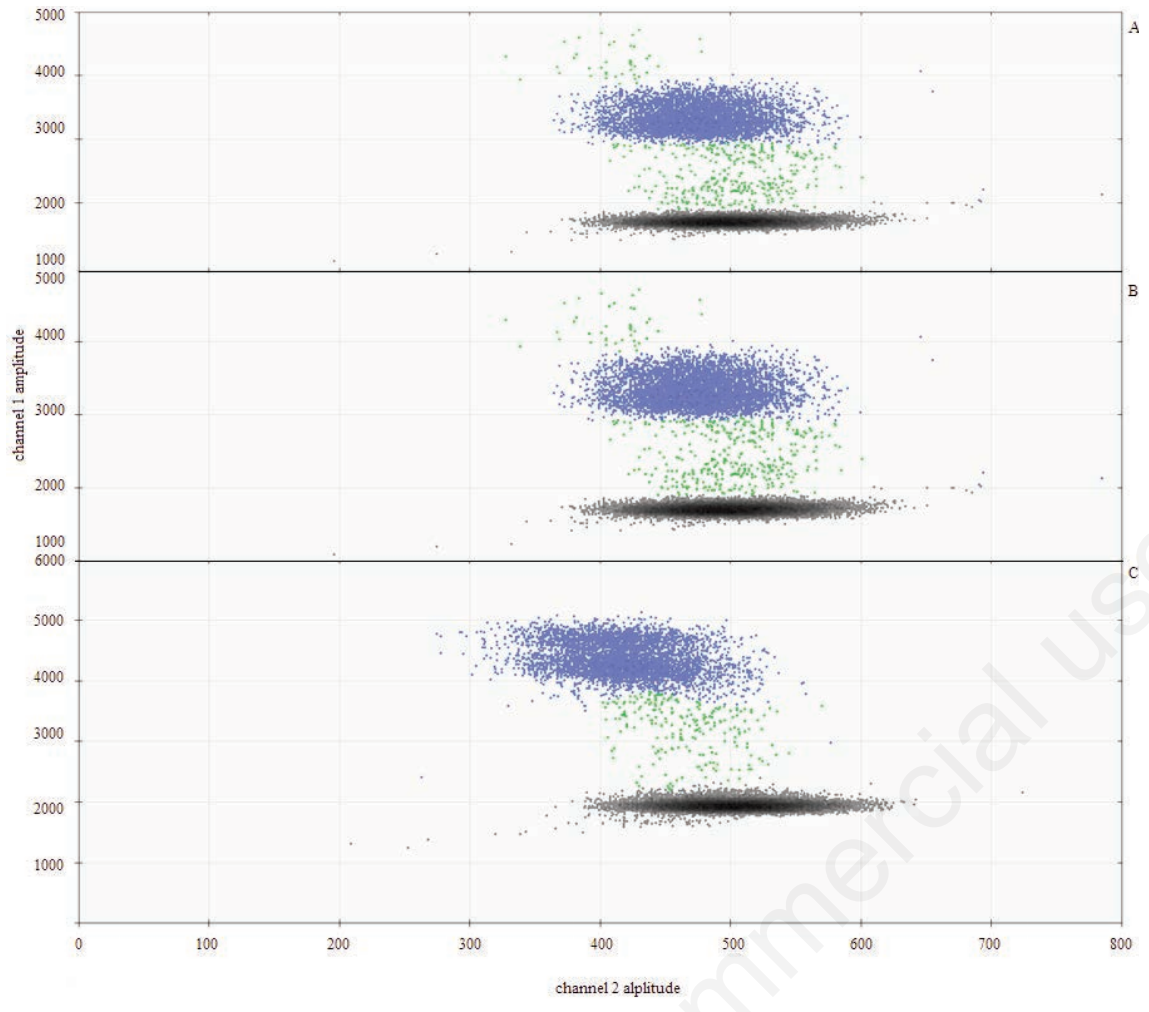

Figure 2. 2-D fluorescence plot in the order A (Gadus morhua), B (Salmo salar), C (Scomber scombrus). because the measured fluorescence is the sum of all amplification processes in the reaction mixture. We can assert that DNA allergen quantification by ddPCR is more accurate compared to $\mathrm{qPCR}$.

In our work the droplet rain was reduced by making gradient annealing and changes of the PCR cycling program, probe and primers concentration with the purpose of increasing the specificity and to improve the assay.

Low concentration of fish detected by ddPCR makes it a promising method to test fish allergen in food.

\section{Conclusions}

To date this is the first study using ddPCR assay to quantify fish allergen. The use of ddPCR demonstrated detection of fish allergen small quantity. Presence of additional reaction products was also observed during ddPCR reactions. These could be result for example of intraspecies variability, SNPs, or interspecies. Further validation studies are needed in order to apply ddPCR technology for specific fish species and for routine allergens analysis.

Furthermore, regulatory guidance on thresholds for allergen in foods it would be desirable with the aim to improve the quality of life for food-allergic consumers.

\section{References}

Cao Y, Raith MR, Griffith JF, 2015. Droplet digital PCR for simultaneous quantification of general and human-
A

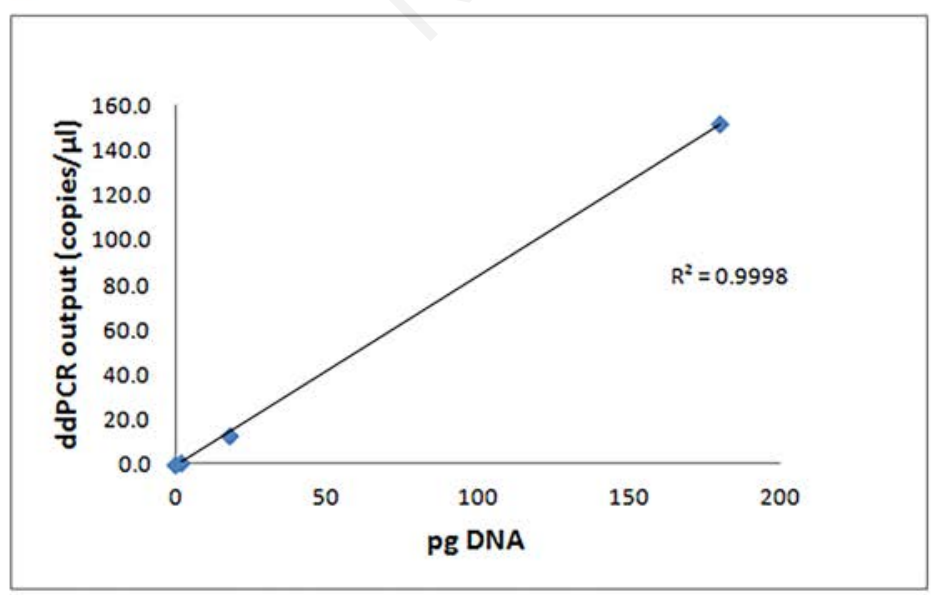

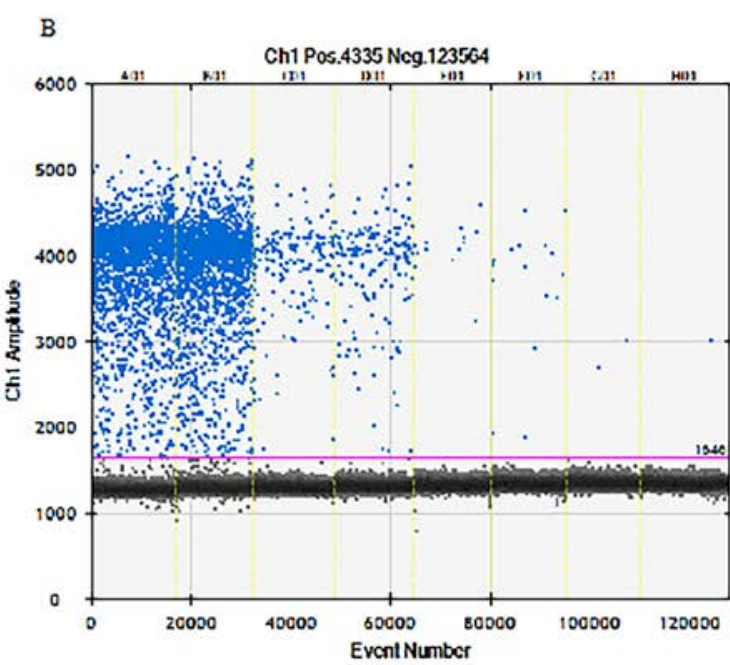

Figure 3. A) Linear relationship between pg DNA (axes X) and copy number concentration (axes Y); B) Ten-fold (from A01 to H01) serial dilutions of DNA from Scomber scombrus in ddPCR. 
associated fecal indicators for water quality assessment. Water Res 70:33749.

European Commission, 2011. Regulation of European Parliament and of the Council of 25 october on the provision of food information to consumers, (EU) $\mathrm{N}^{\circ} 1169 / 2011$ in: O J, L304/18, 22.11.2011

Herrero B, Vieites JM, Espiñeira M, 2014. Development of an in-house fast realtime PCR method for detection of fish allergen in foods and comparison with a commercial kit. Food Chem 151:415-20.

Houhoula D, Dimitriou P, Mengjezi G, Kyrana V, Lougovois V, 2015. Quantification of parvalbumin in commercially important Mediterranean seafood species using real time PCR. Czech J Food Sci 33:143-7.

Hyun-Gwan L, Hye Mi K, Juhee M, Keunyong K, Myung GP, Hae JJ, Kwang YK, 2017. An advanced tool, droplet digital PCR (ddPCR), for absolute quantification of the red-tide dinoflagellate, Cochlodinium polykrikoides (Dinophyceae). Algae 32:189-97.
ISO, 2013. Foodstuffs - Methods of analysis for the detection of genetically modified organisms and derived products Nucleic acid extraction - Amendment 1 UNI EN ISO21571:2005/Amd 1:2013. ISO, Geneva, Switzerland.

Junan R, Tingting D, Wensheng H, Ying, Yiqiang G, 2017. A digital PCR method for identifying and quantifying adulteration of meat species in raw and processed food. PLoS One 12:e173567.

Kim TG, Jeong SY, Cho KS, 2014. Comparison of droplet digital PCR and quantitative real-time PCR for examining population dynamics of bacteria in soil. Appl Microbiol Biotechnol 98:6105-113.

Koppelman SJ, Hefle SL, 2006. Detecting allergens in food. Food Sci Technol 2836.

Morisset D, Dejan S, Milavec M, Kristina G, Jana Z, 2013. Quantitative Analysis of Food and Feed Samples with Droplet Digital PCR. PLoS One 8:e62583.

Scollo F, Egea LA, Gentile A, La Malfa S, Dorado G, Hernandez P, 2016. Absolute quantification of olive oil DNA by droplet digital-PCR (ddPCR):
Comparison of isolation and amplification methodologies. Food Chem 213:388-94.

Shoda K, Ichikawa K, Fujita Y, Masuda K, Hiramoto H, Hamada J, Arita T, Konishi H, Komatsu S, Shiozaki A, Kakihara N, Okamoto K, Taniguchi H, Imoto I, Otsuji E, 2017. Monitoring the HER2 copy number status in circulating tumor DNA by droplet digital PCR in patients with gastric cancer. Gastric Cancer 126-35.

Strain MC, Lada SM, Luong T, Rought SE, Gianella S, Terry VH, 2013. Highly Precise Measurement of HIV DNA by Droplet Digital PCR. PLoS One, 8.

Tetzlaff C, Mäde D, 2017. Development of a realtime PCR system for the detection of the potential allergen fish in food. Eur Food Res Technol 243:849-57.

Witte AK, Mester P, Fister S, Witte M, Schoder D, Rossmanith PP, 2016. A Systematic investigation of parameters influencing droplet rain in the Listeria monocytogenes prfA assay - reduction of ambiguous results in ddPCR. PLoS One 11:e0168179. 